09

\title{
Использование высших мод халькогенидных световодов для оптимизации метода эванесцентной спектроскопии среднего ИК-диапазона
}

\author{
(C) С.В. Корсакова ${ }^{1}$, Е.А. Виноградова ${ }^{1}$, Е.А. Романова ${ }^{1}$, В.С. Ширяев ${ }^{2}$ \\ ${ }^{1}$ Саратовский национальный исследовательский государственный университет им. Н.Г. Чернышевского, \\ Саратов, Россия \\ ${ }^{2}$ Институт химии высокочистых веществ им. Г.Г. Девятых РАН, Нижний Новгород, Россия \\ E-mail: korsakovasv@info.sgu.ru
}

Поступило в Редакцию 16 октября 2018 г.

В окончательной редакции 18 февраля 2019г.

Принято к публикации 18 февраля 2019г.

На основе теоретического подхода, нового для задач эванесцентной спектроскопии, показано, что дисперсионные свойства высших мод многомодового халькогенидного световода, частично погруженного в поглощающую среду, могут быть использованы для создания волоконных устройств, объединяющих функции генератора суперконтинуума и сенсорного элемента спектроскопического датчика среднего ИК-диапазона. Распространение излучения в высших модах позволит управлять положением нуля дисперсии групповой скорости и получать суперконтинуум с накачкой в ближнем ИК-диапазоне. В сенсорном элементе использование высших эванесцентных мод позволит добиться большей чувствительности и расширить динамический диапазон датчика.

DOI: 10.21883/PJTF.2019.10.47750.17565

Волоконные датчики на основе халькогенидных световодов, имеющих малые оптические потери в спектральной области от 1 до $15 \mu \mathrm{m}$ [1], являются потенциально эффективным средством дистанционного химического анализа различных сред в режиме реального времени методом эванесцентной спектроскопии среднего инфракрасного (ИК) диапазона, в котором находятся полосы поглощения колебательных спектров многих органических и неорганических веществ. Использование халькогенидного световода как сенсорного элемента основано на том, что излучение распространяется не только внутри, но и частично вне сердцевины световода. При распространении излучения по бесструктурному световоду, состоящему только из стеклянной сердцевины, происходит уменьшение мощности на длинах волн, соответствующих полосам поглощения внешней среды. Ранее в $[2,3]$ для анализа функционирования и оптимизации волоконного сенсорного элемента мы впервые применили теоретический подход, основанный на представлении излучения, распространяющегося по световоду, в виде эванесцентных мод. На примере мод бесструктурного световода, погруженного в водный раствор ацетона, было показано, что коэффициент затухания в области полос поглощения ацетона больше у эванесцентных мод с высокими радиальными и азимутальными порядками. Это позволяет существенно улучшить выходные характеристики эванесцентного датчика и уменьшить его размеры [4]. Для селективного возбуждения таких мод в световоде нужен источник когерентного излучения. В течение двух последних десятилетий в связи с отсутствием источников суперконтинуума (СК) в среднем ИК-диапазоне метод волоконной эванесцентной спектроскопии был реализован в лабораторных условиях в совокупности с фурье-спектрометрами [5-8]. В последнее время появились источники СК на основе халькогенидных световодов в диапазоне длин волн $\lambda$ от 3 до более чем $10 \mu \mathrm{m}$ [9-11], но при отсутствии волоконных лазеров среднего ИК-диапазона для накачки СК используются перестраиваемые по частоте параметрические генераторы, что существенно увеличивает стоимость экспериментальных исследований. Поскольку нули дисперсии групповой скорости (ДГС) халькогенидных стекол приходятся на область $\lambda>4 \mu \mathrm{m}$, для получения СК с накачкой в области $\lambda=1.5-2.5 \mu$ m необходимо компенсировать нормальную ДГС халькогенидных стекол в ближнем ИК-диапазоне. Для этой цели обычно используются маломодовые световоды или микроструктурированные световоды с подвешенной сердцевиной. Большая волноводная дисперсия фундаментальной моды позволяет получить нули полной ДГС в области меньших $\lambda$. Однако, если размеры сердцевины сравнимы с $\lambda$, возникают большие потери при вводе излучения накачки. Поскольку СК в среднем ИК-диапазоне нужен в основном для спектрального анализа, согласование источника СК и волоконного сенсорного элемента является важной задачей оптимизации характеристик волоконного спектроскопического датчика.

В настоящей работе впервые исследуется возможность создания волоконного сенсорного элемента на основе многомодового халькогенидного световода, в котором будет осуществляться также и генерация СК, так как для компенсации дисперсии халькогенидного стекла 

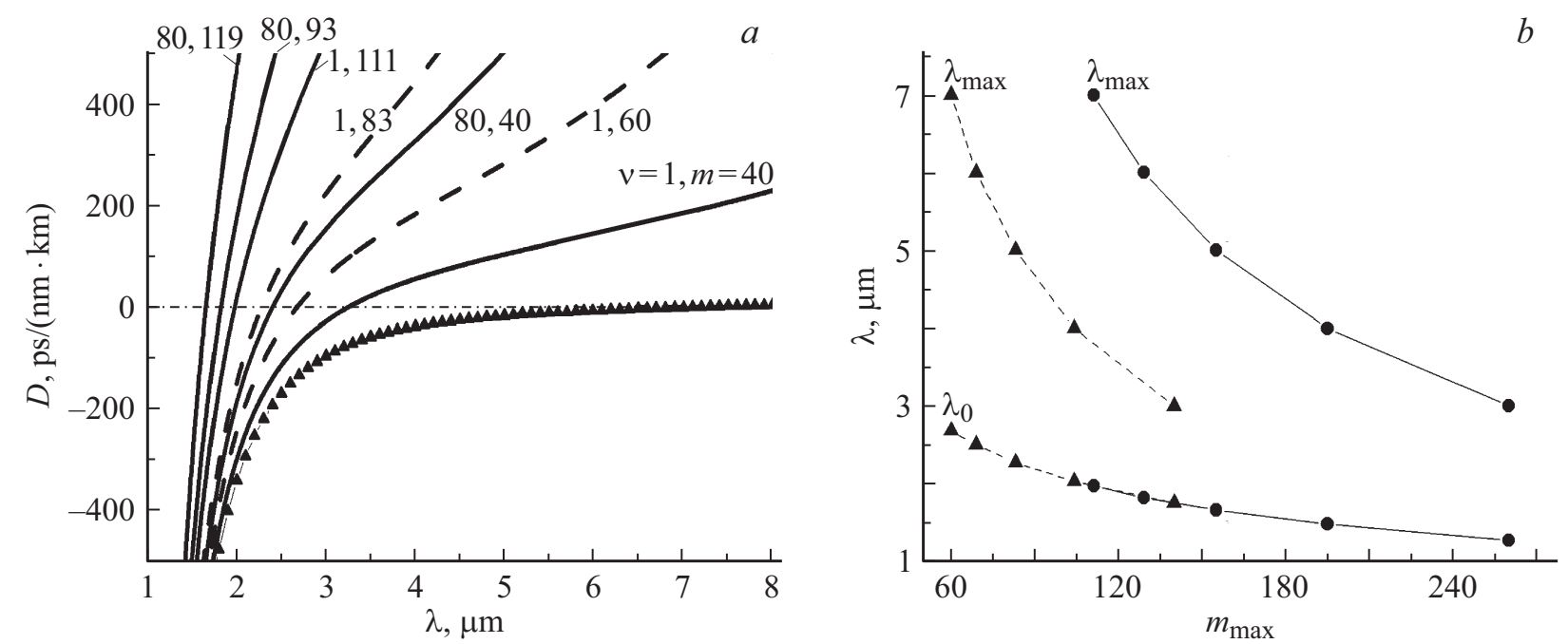

Рис. 1. $a$ - спектральная зависимость параметра $D$ для мод $\mathrm{HE}_{v m}$ световода с $R=150 \mu$ m из стекла состава $\mathrm{As}_{2} \mathrm{Se}_{3}$ в воздухе (сплошные линии) и с оболочкой из стекла состава $\mathrm{As}_{2} \mathrm{~S}_{3}$ (штриховые линии). Треугольниками показана спектральная зависимость $D=-\lambda / c\left(d^{2} n / d \lambda^{2}\right)$ для стекла состава $\mathrm{As}_{2} \mathrm{Se}_{3} . b-$ нули ДГС $\lambda_{0}$ для мод $\mathrm{HE}_{1 m}$ с индексом $m_{\max }$ на длине волны $\lambda_{\text {max }}$ световода из стекла состава $\mathrm{As}_{2} \mathrm{Se}_{3}$ в воздухе (кружки) и с оболочкой из стекла состава $\mathrm{As}_{2} \mathrm{~S}_{3}$ (треугольники).

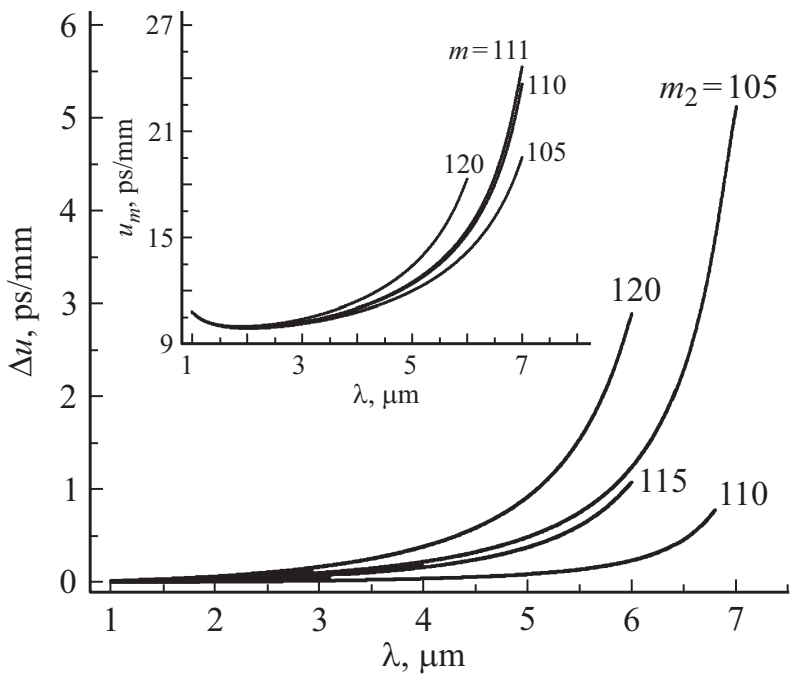

Рис. 2. Спектральная зависимость разностей групповых скоростей мод $\mathrm{HE}_{1 m}$ бесструктурного световода с $R=150 \mu \mathrm{m}$ из стекла состава $\mathrm{As}_{2} \mathrm{Se}_{3}, m_{1}=111$. На вставке - спектральная зависимость групповых скоростей отдельных мод $\mathrm{HE}_{1 m}$.

в ИК-диапазоне может быть использована волноводная дисперсия мод с высокими порядками. Генерация СК в высших модах маломодовых халькогенидных световодов с диаметром сердцевины $d$ порядка $\lambda$ рассчитывалась, например, в [12]. Однако исходя из технологических предпочтений для сенсорного элемента эванесцентного датчика нужны бесструктурные световоды с $d>100 \mu \mathrm{m}$. Так, в $[2,3,5-8]$ для измерений использовались световоды с $d$ от 200 до $500 \mu \mathrm{m}$.

Рассмотрим многомодовый световод с сердцевиной из стекла состава $\mathrm{As}_{2} \mathrm{Se}_{3}$ - как бесструктурный, так и с бесконечной оболочкой из стекла состава $\mathrm{As}_{2} \mathrm{~S}_{3}$. Показатели преломления стекол в области $\lambda=1-8 \mu \mathrm{m}$ рассчитываются по формулам Зельмейера [13]. Поскольку показатель преломления стекла $\mathrm{As}_{2} \mathrm{Se}_{3}(\sim 2.8$ в среднем ИК-диапазоне) значительно больше показателя преломления воздуха, а также стекла $\mathrm{As}_{2} \mathrm{~S}_{3}(\sim 2.4$ в среднем ИК-диапазоне), приближение слабонаправляющего световода [14] в данном случае неприменимо. Поэтому для получения дисперсионных характеристик мод проводится численное решение строгого характеристического уравнения [14]:

$$
\begin{gathered}
{\left[\frac{J_{v}^{\prime}(u)}{u J_{v}(u)}+\frac{K_{v}^{\prime}(w)}{w K_{v}(w)}\right]\left[\frac{J_{v}^{\prime}(u)}{u J_{v}(u)}+\frac{n_{2}^{2}}{n_{1}^{2}} \frac{K_{v}^{\prime}(w)}{w K_{v}(w)}\right]} \\
=\left(\frac{v \beta}{k n_{1}}\right)^{2}\left(\frac{V}{u w}\right)^{4},
\end{gathered}
$$

где $v-$ азимутальный порядок моды, $J_{v}$ и $K_{v}-$ функции Бесселя и Макдональда, $J_{v}^{\prime}$ и $K_{v}^{\prime}-$ их производные, $u$ и $w$ - параметры моды в сердцевине и оболочке соответственно, $\beta=\sqrt{k^{2} n_{1}^{2}-u^{2} / R^{2}}-$ продольная постоянная распространения моды, $k=2 \pi / \lambda, R=d / 2, n_{1}$ и $n_{2}-$ показатели преломления сердцевины и оболочки соответственно, $V=k R \sqrt{n_{1}^{2}-n_{2}^{2}}$. Корни уравнения (1) с $v=0$ соответствуют модам $\mathrm{TE}_{0 m}$ и $\mathrm{TM}_{0 m}$ [14]. При решении (1) с $v \neq 0$ в качестве начального приближения берем корни характеристических уравнений мод $\mathrm{HE}_{v m}$ и $\mathrm{EH}_{v m}$ слабонаправляющего световода. Поэтому при анализе корней уравнения (1) нами используется классификация мод, принятая в теории слабонаправляющих световодов [14]. Параметр ДГС $D=-\left(2 \pi c \beta_{2}\right) / \lambda^{2}$ (где $\beta_{2}=d^{2} \beta / d \omega^{2}, c-$ скорость света в вакууме) рассчи- 

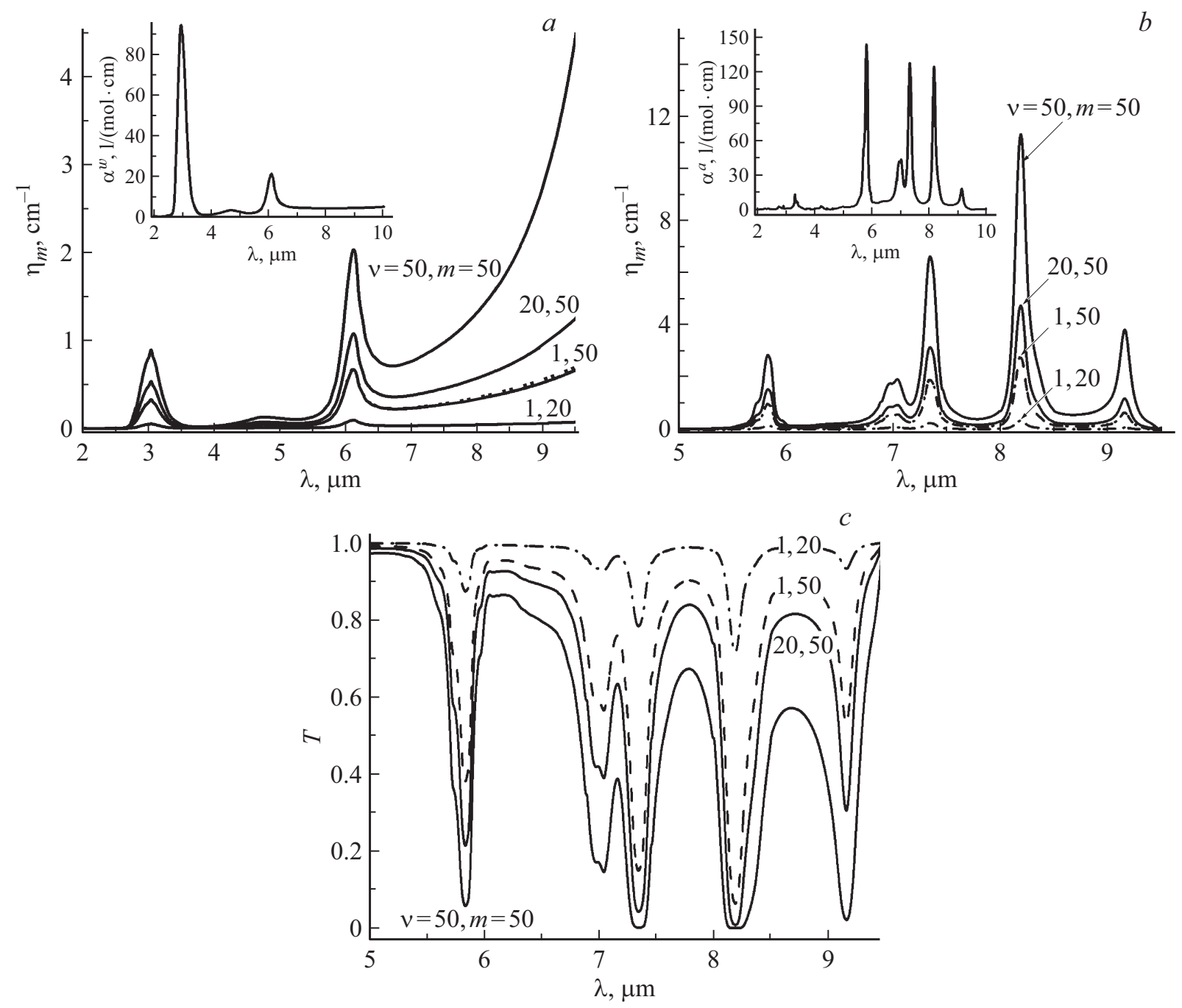

Рис. 3. Спектральные зависимости коэффициентов затухания $\eta_{m}$ мод $\mathrm{HE}_{v m}$ бесструктурного световода с $R=150 \mu \mathrm{m}$ и $L=1 \mathrm{~cm}$ из стекла состава $\mathrm{As}_{2} \mathrm{Se}_{3}$, погруженного в воду (на вставке - молярный коэффициент поглощения $\alpha^{w}$ воды) (a) и чистый ацетон (на вставке - молярный коэффициент поглощения $\alpha^{a}$ ацетона) $(b) . c$ - пропускание $T$ световода, погруженного в чистый ацетон, рассчитанное для отдельных мод $\mathrm{HE}_{v m}$. На части $a$ пунктиром показаны коэффициенты затухания моды $\mathrm{TE}_{0 m} \mathrm{c} m=50$.

тывался для мод световода с $R=150 \mu \mathrm{m}$ в диапазоне $\lambda=1-8 \mu \mathrm{m}$. Оказалось, что величины $\beta$ и $D$, полученные для мод $\mathrm{TE}_{0 m}, \mathrm{TM}_{0 m}$ и $\mathrm{HE}_{1 m}$ и $\mathrm{EH}_{1 m}$ с одинаковым радиальным индексом $m$, имеют близкие значения при малых $m$, поскольку в этом случае $k^{2} n_{1}^{2} \gg u^{2} / R^{2}$. У мод с большим $m$, близких к отсечке, когда $u \rightarrow V$, значения $D$ различаются сильнее. Однако длина волны $\lambda_{0}$, соответствующая $D=0$, у этих мод различается не более чем на $1-2 \%$. Поэтому в дальнейшем изложении дисперсионные характеристики представлены для мод $\mathrm{HE}_{1 m}$, а также для мод $\mathrm{HE}_{v m} \mathrm{c} v>1$.

Поскольку число направляемых мод уменьшается с ростом $\lambda$, в задаче о генерации СК в отдельно взятой моде необходимо выбрать спектральный интервал, в котором рассматриваемая мода не уйдет за отсечку при нелинейном преобразовании частоты. Для каждой длины волны $\lambda_{\max }$ определялась мода с наибольшим $m\left(m_{\max }\right)$, а параметр $D$ рассчитывался для этой моды в области $\lambda$ от $1 \mu \mathrm{m}$ до $\lambda_{\max }$. Оказалось, что любая направляемая мода рассматриваемых световодов в той или иной степени позволяет уменьшать $\lambda_{0}$ относительно нуля ДГС стекла состава $\mathrm{As}_{2} \mathrm{Se}_{3}\left(\lambda_{0}=7.1 \mu \mathrm{m}\right)$ (рис. $\left.1, a\right)$. Смещение $\lambda_{0}$ в область меньших $\lambda$ растет как при фиксированном $v$ с увеличением $m$, так и при фиксированном $m$ с увеличением $v$. Из рис. $1, b$ видно, что при увеличении $\lambda_{\max }$ от 3 до $7 \mu \mathrm{m}$ значение $\lambda_{0}$, полученное для мод бесструктурного световода, уменьшается от 1.9 до $1.25 \mu \mathrm{m}$, а в случае световода со стеклянной оболочкой - от 2.6 до $1.75 \mu \mathrm{m}$. Моды бесструктурного световода с большими $m_{\max }$, имеющие $\lambda_{0}$ в области $\lambda \sim 1.56 \mu \mathrm{m}$ (длина волны генерации эрбиевого лазера), могут распространяться как направляемые при $\lambda<4 \mu \mathrm{m}$ и, таким образом, не подходят для генерации СК в среднем ИК-диапазоне. Выбирая моды с меньшими $m_{\max }$, 
можно продвинуться в область больших $\lambda$, но ценой некоторого увеличения $\lambda_{0}$ и соответственно увеличения $\lambda$ накачки до $2 \mu \mathrm{m}$. В случае световода со стеклянной оболочкой с такой накачкой можно получить СК в области $\lambda<4 \mu \mathrm{m}$, а для продвижения в длинноволновую область нужна накачка с $\lambda>2 \mu \mathrm{m}$. При использовании световода с меньшим $R$ длина волны $\lambda_{0}$ у всех мод уменьшается, но при этом сокращается и число мод на каждой длине волны.

Селективное возбуждение высших мод можно осуществить разными способами, например путем ввода лазерного пучка под углом к оси световода. Так, в работе [6] для этого использовались специальные маски, перекрывающие часть пучка излучения теплового источника, сфокусированного на торец световода. При этом возможно возбуждение нескольких мод. Для оценки вклада межмодовой дисперсии нужно сравнить групповые скорости отдельных мод и разности этих скоростей. На примере мод $\mathrm{HE}_{1 m}$ оценим групповые скорости $u_{m}=d \beta_{m} / d \omega$ и их разности $\Delta u=\left|u_{m_{2}}-u_{m_{1}}\right|$, рассчитанные для моды с $m_{1}=111$ (на рис. 1 для этой моды $\left.\lambda_{0} \sim 2 \mu \mathrm{m}\right)$ и ближайших к ней мод с индексами $m_{2}$ (рис. 2). В области нулей ДГС, которым соответствуют минимумы зависимостей $u_{m}(\lambda)$ на вставке к рис. $2, \Delta u$ на порядок меньше $u_{m}$. При увеличении $\lambda$ разности групповых скоростей растут, но моды с $m_{2}>111$ уже не являются направляемыми в области $\lambda>6 \mu \mathrm{m}$. Таким образом, в рассмотренном случае на заданной длине световода $L$ групповые задержки $u_{m} L$ отдельных мод значительно больше, чем $\Delta u L$, т.е. преобладает внутримодовая дисперсия. В общем случае вклад межмодовой дисперсии определяется исходя из условий селективного возбуждения мод.

Если рассмотренный световод используется и как сенсорный элемент, т. е. на некоторой длине погружен в поглощающую среду, все направляемые моды становятся эванесцентными. Комплексные постоянные распространения $\beta=\beta^{\prime}+i \beta^{\prime \prime}$ этих мод определяются, как показано в [2], путем решения (1) с комплексным $n_{2}$. Рассчитаем коэффициенты затухания $\eta_{m}=2 \beta_{m}^{\prime \prime}$ эванесцентных мод бесструктурного световода, погруженного в воду или ацетон, в области $\lambda=1-8 \mu \mathrm{m}$. Оказалось, что у моды $\mathrm{HE}_{v m}$ на заданной длине волны $\lambda$ значения $\eta_{m}$ растут при увеличении $v$ (рис. $3, a, b)$, так как соответственно растет доля мощности моды в оболочке [14]. У мод $\mathrm{HE}_{1 m}$ и $\mathrm{TE}_{0 m}$ разница значений $\eta_{m}$ невелика и растет при увеличении $m$, поскольку доля мощности в оболочке у моды $\mathrm{TE}_{0 m}$ становится несколько больше, чем у моды $\mathrm{HE}_{1 m}$ с тем же $m$. Отметим, что $\eta_{m}$ каждой моды растет с $\lambda$, так что, например, $\eta_{m}$ мод световода, погруженного в воду, имеют максимальные значения при больших $\lambda$ в отличие от коэффициентов молярного поглощения, показанных на вставках к рис. $3, a, b$. Соответственно падает по спектру пропускание $T$ сенсорного элемента (рис. 3,c) (при расчете пропускания предполагалось, что вся входная мощность распространяется в одной моде световода). Отметим, что наличие поглощения во внешней среде практически не влияет на дисперсионные свойства мод.

Таким образом, в настоящей работе установлено, что функции генератора СК в среднем ИК-диапазоне и сенсорного элемента могут быть реализованы в одном многомодовом халькогенидном световоде. Это позволит избежать трудностей, которые возникают при согласовании одномодового волоконного генератора СК как с лазером накачки, так и с многомодовым сенсорным элементом. Однако для предложенного нами способа оптимизации волоконного эванесцентного датчика необходимо разработать методики селективного возбуждения мод световода с высокими порядками. Дисперсионные свойства таких мод, как показано в настоящей работе, позволяют компенсировать нормальную ДГС халькогенидного стекла в ИК-диапазоне, уменьшая соответственно $\lambda_{0}$. Эффективность нелинейного преобразования частоты накачки значительно повышается вблизи нуля ДГС заданной моды световода. При наличии фазового синхронизма возможно преобразование частоты и в других модах [15]. Использование мод с высокими порядками позволяет увеличить эффективность нелинейной модуляции фазы в волоконном световоде, которая определяется величиной $I n_{K} / A_{e f f}$, где $I-$ интенсивность, $n_{K}$ - керровская постоянная, $A_{e f f}$ - эффективная площадь моды. Поскольку поперечные профили мод $\mathrm{HE}_{1 m}$ и $\mathrm{TE}_{0 m}$ с $m>1$ имеют кольцевую структуру, а моды $\mathrm{HE}_{v m}$ имеют внутренние каустики, можно не только уменьшить $A_{e f f}$, но и избежать самофокусировки светового пучка в световоде при большой интенсивности. Отметим, что величина $n_{K}$ в халькогенидных стеклах на два-три порядка больше, чем у кварцевого стекла [13]. За счет использования мод с высокими порядками в сенсорном элементе, как было показано нами ранее в [4], можно увеличить чувствительность и диапазон измеряемых значений волоконного эванесцентного датчика.

Представленные нами в настоящей работе и в [2-4] результаты получены в рамках теоретического подхода, основанного на модовом представлении электромагнитного поля, распространяющегося в волоконном световоде. Такой подход, новый для задач эванесцентной спектроскопии, является основой для перспективных разработок волоконных спектроскопических датчиков.

\section{Финансирование работы}

Работа выполнена при поддержке гранта Российского научного фонда (проект № 16-13-10251).

\section{Список литературы}

[1] Shiryaev V.S., Churbanov M.F. // J. Non-Cryst. Solids. 2013. V. 377. P. 225-230.

[2] Romanova E.A., Korsakova S., Komanec M., Nemecek T., Velmuzhov A., Sukhanov M., Shiryaev V.S. // IEEE J. Sel. Top. Quant. Electron. 2017. V. 23. N 2. P. 1-7. 
[3] Korsakova S., Romanova E., Velmuzhov A., Kotereva T., Sukhanov M., Shiryaev V.S. // J. Non-Cryst. Solids. 2017. V. 475. P. 38-43.

[4] Корсакова С.В., Романова Е.А., Вельмужов А.П., Котерева Т.В., Суханов М.В., Ширяев В.С. // Оптика и спектроскопия. 2018. Т. 125. В. 3. С. 402-410.

[5] Heo J., Rodrigues M., Saggese S.J., Sigel G.H. // J. Appl. Opt. 1991. V. 30. N 6. P. 3944-3951.

[6] Katz M., Katzir A., Schnitzer I., Bornstein A. // J. Appl. Opt. 1994. V. 33. N 25. P. 5888-5894.

[7] Sanghera J.S., Kung F.H., Pureza P.C., Nguyen V.Q., Miklos R.E., Aggarwal I.D. // J. Appl. Opt. 1994. V. 33. N 27. P. 6315-6322.

[8] Sanghera J.S., Kung F.H., Busse L.E., Pureza P.C., Aggarwal I.D. // J. Am. Ceram. Soc. 1995. V. 78. N 8. P. 2198 2202.

[9] Kubat I., Agger C.S., Moller U., Seddon A.B., Tang Z., Sujecki S., Benson T.M., Furniss D., Lamrini S., Scholle K., Fuhrberg P., Napier B., Farries M., Ward J., Moselund P.M., Bang O. // Opt. Express. 2014. V. 22. N 16. P. 19169-19182.

[10] Petersen C.R., Mфller U., Kubat I., Zhou B., Dupont S., Ramsay J., Benson T., Sujecki S., Abdel-Moneim N., Tang Z., Furniss D., Seddon A., Bang O. // Nature Photon. 2014. V. 8. P. 830-834.

[11] Møller U., Yu Y., Kubat I., Petersen C.R., Gai X., Brilland L., Méchin D., Caillaud C., Troles J., Luther-Davies B., Bang O. // Opt. Express. 2015. V. 23. N 3. P. 3282-3291.

[12] Wang N., Habib M.S., Jia F., Li G., Amezcua-Correa R. // Proc. Conf. 2018 IEEE Photonics Society Summer Topical Meeting Series (SUM). IEEE, 2018. P. 135-136.

[13] Zakery A., Elliot S.R. Optical nonlinearities in chalcogenide glasses and their applications Berlin-Heidelberg-N.Y.: Springer-Verlag, 2007. $202 \mathrm{p}$.

[14] Snyder W., Love J.D. Optical waveguide theory. London: Chapman and Hall, 1983. 734 p.

[15] Агравал Г. Нелинейная волоконная оптика. М.: Мир, 1996. $323 \mathrm{c}$. 